\title{
Statistical Analysis of Input Parameters Impact on the Modelling of Underground Structures
}

\author{
M. Hilar, J. Pruška
}

The behaviour of a geomechanical model and its final results are strongly affected by the input parameters. As the inherent variability of rock mass is difficult to model, engineers are frequently forced to face the question "Which input values should be used for analyses?" The correct answer to such a question requires a probabilistic approach, considering the uncertainty of site investigations and variation in the ground. This paper describes the statistical analysis of input parameters for FEM calculations of traffic tunnels in the city of Prague. At the beginning of the paper, the inaccuracy in the geotechnical modelling is discussed. In the following part the Fuzzy techniques are summarized, including information about an application of the Fuzzy arithmetic on the shotcrete parameters. The next part of the paper is focused on the stochastic simulation - Monte Carlo Simulation is briefly described, Latin Hypercubes method is described more in details. At the end several practical examples are described: statistical analysis of the input parameters on the numerical modelling of the completed Mrázovka tunnel (profile West Tunnel Tube km 5.160) and modelling of the constructed tunnel Špejchar - Pelc Tyrolka.

Keywords: Finite element method, input parameters, rock mass, Fuzzy, LHS sampling, Monte Carlo method, numerical model, underground structures.

\section{Introduction}

The inherent variability of a rock mass is difficult to model and for this reason engineers very often have to ask the question "What value should be used in analyses?" The answer to such question requires a probabilistic approach in the evaluating the uncertainty in the input parameters in geologic media. In the recent times, specialists have encountered problems in the input parameters derived from uncertainty modelling based on the Fuzzy set theory, Monte Carlo Simulation, Latin Hypercube Sampling etc.

\section{Fuzzy methods}

In the design of underground structures, it is very difficult to take into account the inherent variability of rock mass using the current rock mass classifications. One of the main means of improving rock mass classification is by accounting for variations in the individual parameters using fuzzy mathematics [1]. The fuzzy set was first introduced in 1965 by Lofti A. Zadeh [2] as a mathematical way to represent linguistic vagueness. In a classical set, an element either belongs to or does not belong to a set. The concepts and definitions of the fuzzy set theory are described in many publications. Dubois and Pride [3] provide the following definition: "Fuzzy set is a generalization of ordinary or classical set theory. It consists of mathematical tools developed to model and process incomplete and/or gradual information, ranging from interval - valued numerical data to symbolic and linguistic expressions". Contrary to crisp (or ordinary) sets, fuzzy sets have no sharp or precise boundaries. In crisp sets, element $x$ belongs to or does not belong to a set $A$ and the membership function (or degree of membership) $\mu_{A}(x)$ is unique. Fuzzy sets assign the membership function $\mu_{A}(x)$ for each element $x$ as a range over the interval ( 0 to 1$)$. This type of membership function is characterised by a smooth transition from "belonging to a set" (1) to "not belonging to a set" (0) and gives fuzzy sets flexibility in modelling based on linguistic expres- sions of engineering practice (such as "fairly rough surface"). Membership functions can also be represented in analytical methods.

Two types of variables are used in the fuzzy model: fuzzy variables and fuzzy numbers. Fuzzy variables are defined directly as fuzzy sets based on a group of reference linguistic terms. Generally, a fuzzy variable xj can acquire any value between the reference terms. For the linguistic terms the fuzzy variables are fuzzy singletons. Fuzzy variables need not to be associated with any numerical universe. This can be because their values are qualitative in nature, or because they are treated as qualitative for the sake of convenience. Fuzzy numbers are defined over a continuous domain - triangular or trapezoidal membership functions (or numbers). Trapezoidal number is defined by the height and four distinct elements of the fuzzy set interval. Fuzzy Logic provides a number of functions for performing fuzzy arithmetic. The fuzzy arithmetic functions are a little different from the rest of Fuzzy Logic's functions in that they operate on lists of fuzzy numbers.

The application of fuzzy arithmetic in the rock mass classification is direct and generates a fuzzy number representing the classification value. Fuzzy mathematics even introduces the uncertainty in the evaluating of parameters in the rock mass classification. Let us take, for example, the Index $Q$ rock mass classification. This classification was established in 1974 in Norway (by Barton, Lien, Lunde and Loset) and is based on six parameters [4]:

$$
Q=\frac{R Q D}{J_{n}} \cdot \frac{J_{r}}{J_{a}} \cdot \frac{J_{w}}{S R F},
$$

where $R Q D=$ rock quality designation, $J_{n}=$ joint set number, $J_{a}=$ joint alteration number, $J_{w}=$ joint water reduction number, $S R F=$ stress reduction factor.

By applying fuzzy logic to the equations for the Index $Q$ (Equation 1), we obtain results in the fuzzy classification value with non-linear distributions. The convex nature of the flanks 
has the effect of increasing the possibility that the conditions will be worse than a single computed index $Q$.

\section{Monte Carlo simulation}

Monte Carlo simulation is a well-known tool that is used to analyze random phenomena. In the Monte Carlo simulation, a random problem is transformed into several deterministic problems that are much easier to solve - sample inputs are used to generate sample outputs with statistical or probabilistic information about the random output quantity. Monte Carlo simulation is simple to use and therefore has found much favour in geomechanics, particularly in stability analysis of rock slopes [5].

The simplest sampling scheme of a Monte Carlo simulation approach is to use a pseudorandom number generator to select random numbers between 0 and 1 and use them to generate values for each variable which is an input to the calculation. However, this simple (and best-known) random sampling scheme requires many samples for good accuracy and repeatability - in practice, generating a probability distribution of the safety factor of a rock slopes requires a minimum of 200 up to 2000 selections (depending on the desired accuracy).

The simulation output (random variable which depends upon random input variables, fields and processes) may be presented in several ways.

One way is to define the probability that a safety factor $F$ is less than a prescribed value $F_{0}$ :

$$
P\left(F<F_{0}\right)=\frac{n}{N},
$$

where $n=$ number of trials in which $F<F_{0}, N=$ number of selections.

Another approach [6] is to plot a cumulative distribution of $F$, which can be used to determine the probability of $F$ being less than a given value.

\section{Latin hypercube sampling (LHS)}

Other sampling methods have been developed to reduce the number of samples required for good accuracy in the Monte Carlo simulation. One of the best is Latin hypercube sampling [7]. Latin hypercube sampling preserves marginal probability distributions for each simulated variable (Fig. 1). To fulfilled this aim, Latin hypercube sampling constructs a highly depend joint probability density function for the random variables in the problem, which allows good accuracy in the response parameter even when using only a small number of samples.

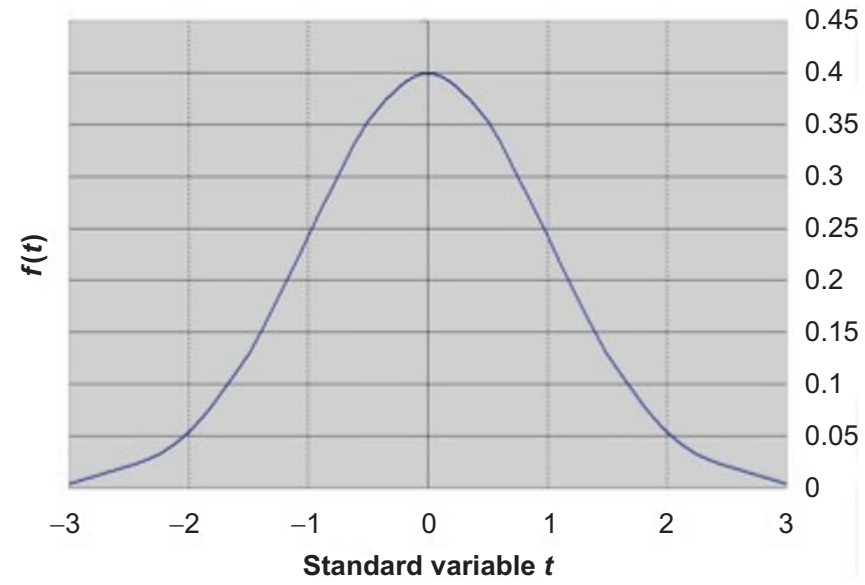

Fig. 1: Probability density function - Gaussian distribution

In Latin hypercube sampling, the bounded interval $\langle 0,1\rangle$ is uniformly divided into $N$ non-overlaying intervals - Fig. 2 (with the same probability of accuracy). One value per interval is generated afterwards. This can be performed by initially generating $N$ random numbers within range $\langle 0,1\rangle$. These values are linearly transformed to the random numbers in the non-overlaying intervals for each random variable:

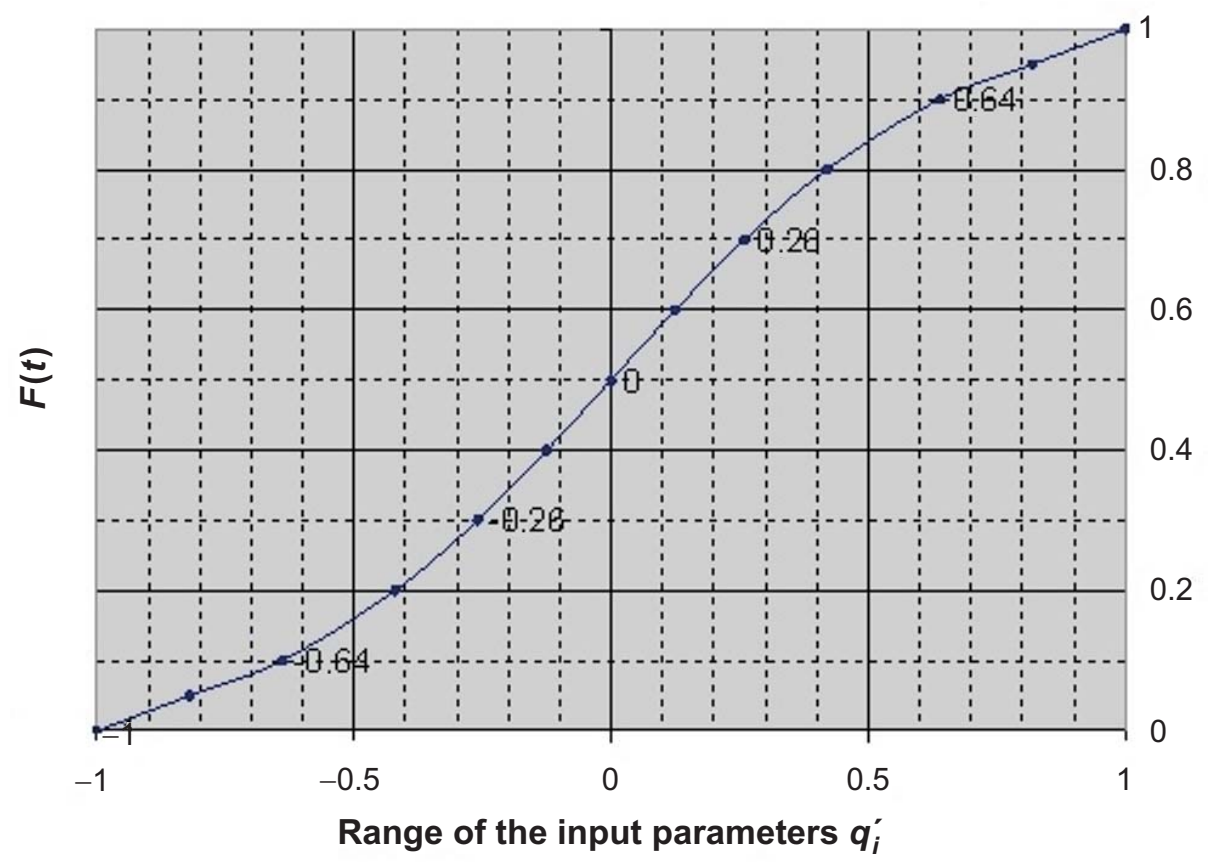

Fig. 2: Dividing the distribution function into intervals 


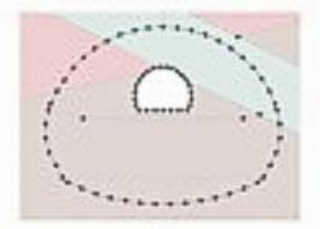

a

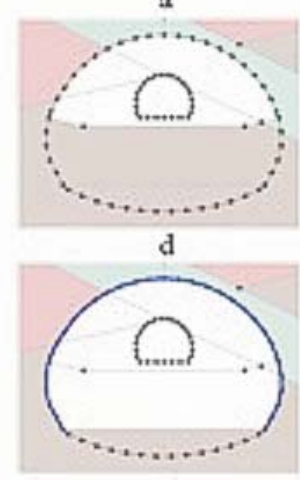

B

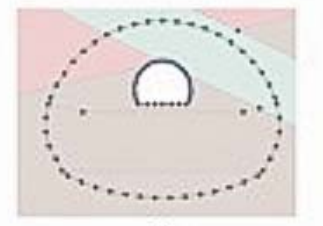

b

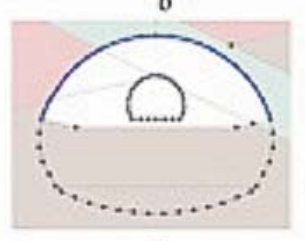

e

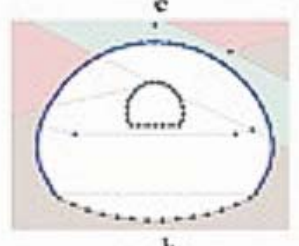

h
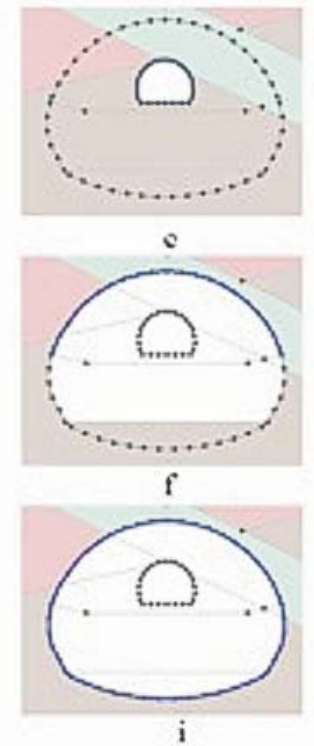

Fig. 3: Numerical modelling stages

$$
u_{i}=\frac{u}{N}+\frac{(i-1)}{N},
$$

where $i=1,2, \ldots, n$ ( $n$ number of values), $u=\mathrm{a}$ random number $(u \in\langle 0,1\rangle), u_{i}=$ random numbers in the $i^{\text {th }}$ interval, $N=$ number of the non-overlaying intervals.

From the above equation, it follows that we generate only one value for each random variable (this value is randomly selected within each of $N$ intervals):

$$
\frac{(i-1)}{N}<u_{i}<\frac{1}{N},
$$

where $i=1,2, \ldots, n$ ( $n$ number of values), $u_{i}=$ a random numbers in the $i^{\text {th }}$ interval, $N=$ number of the non-overlaying.

The $n$ values obtained for the first random variable $x_{1}$ are paired in a random manner with the values of the second random variable. These $n$ pairs of $\left(x_{1}, x_{2}\right)$ are combined in a random manner with $n$ values of the third random variable. This combination results in the $n$ triads $\left(x_{1}, x_{2}, x_{3}\right)$ which are combined with $n$ values of the $4^{\text {th }}$ random variable and so on until $(K-2)$ triads are formed $(K$ is a number of random variables). Thus we can assemble an $N * K$ matrix. It can be seen that certain statistical correlations between columns of the matrix may have a significant influence on the results of simulation [8].

\section{Construction of tunnels in Prague}

The north-western sector of the City Circular Road in Prague contains three major road tunnels of large cross section area. While the Strahov and Mrázovka tunnels are already open for traffic, the Špejchar - Pelc Tyrolka tunnel is still in the planning phase. The very difficult geological conditions in the Prague Ordovician make it necessary to use NATM mehods. Stabilization of the deformations was achieved only after closure of the whole primary lining, but the following interim supporting technical measures were performed: anchoring, widening of the top heading legs, micropile support under the top heading legs, reinforcing grouting performed in advance from the exploratory gallery, and closing the top heading by a temporary invert. Due to increased deformations occurring at the excavation with a horizontally divided face, a sequence with a vertical pattern was used in the further course of excavating the Mrázovka tunnel.

\section{Modelling of the Mrázovka tunnel}

The outputs of the Mrázovka tunnel modelling were verified by the Latin Hypercubes method [9]. The numerical analysis was carried out by means of the PLAXIS program system. The 3D behaviour of the excavation face area, and correct description of the influence on the deformations and the state of the massif were simulated by the common procedure of loading the excavation and lining using the so-called $\beta$-method (Fig. 3). The modelled area of the profile was approximately $200 \mathrm{~m}$ wide and $110 \mathrm{~m}$ high and was divided into eight basic sub-areas according to the types of rock encountered (Fig. 4). The rock mass behaviour was approximated by means of the Mohr-Coulomb model. The input geotechnical parameters of the rock mass $\left(E_{\text {def }}, \nu, c, \varphi, \gamma\right)$ were determined on the basis of the engineering-geological investigation results - Tables 1, 2 and 3 [10]. A comparison of theoretically determined deformations with the values obtained by monitoring [11] was used to verify the applicability of the mathematical model. The results of the statistical study of the West Tunnel Tube (WTT) in profile km 5.160 are shown in Table 4 . They show that the probability of final settlements being between $71 \mathrm{~mm}$ and $213 \mathrm{~mm}$ is $95 \%$. The range of settlement without including deformations caused by the excavation of the pilot adit is $65 \mathrm{~mm}$ to $198 \mathrm{~mm}$. The predicted range was consistent with the measured value of $194 \mathrm{~mm}$ (value does not include effect of pilot adit).

\section{Modelling of the Špejchar - Pelc-Tyrolka tunnel}

The Špejchar - Pelc-Tyrolka project is $4.320 \mathrm{~m}$ long with the length of the tunnelled section being $3.438 \mathrm{~m}$ [12]. As well 
Table 1: Input $\phi$ values for various geotechnical layers based on random intervals

\begin{tabular}{|c|c|c|c|c|c|c|c|}
\hline Number of calculation & $\mathrm{a}$ & $\mathrm{b}$ & $\mathrm{In}=1$ & In $=2$ & In $=3$ & In $=4$ & In $=5$ \\
\hline Value $q_{i j}^{\prime}$ & -1 & 1 & -0.64 & -0.26 & 0.00 & 0.26 & 0.64 \\
\hline Ground 1 & 25 & 27 & 25.4 & 25.6 & 26.0 & 26.4 & 26.6 \\
\hline Ground 2 & 27 & 29 & 27.4 & 27.6 & 28.0 & 28.4 & 28.6 \\
\hline Ground 3 & 22 & 25 & 22.5 & 22.9 & 23.5 & 24.1 & 24.5 \\
\hline Ground 4 & 25 & 30 & 25.9 & 26.5 & 27.5 & 28.6 & 29.1 \\
\hline Ground 5 & 30 & 35 & 30.9 & 31.5 & 32.5 & 33.6 & 34.1 \\
\hline Ground 6 & 35 & 38 & 35.5 & 35.9 & 36.5 & 37.1 & 37.5 \\
\hline Ground 7 & 35 & 38 & 35.5 & 35.9 & 36.5 & 37.1 & 37.5 \\
\hline Ground 8 & 25 & 28 & 25.5 & 25.9 & 26.5 & 27.1 & 27.5 \\
\hline
\end{tabular}

Table 2: Random permutations of the input parameters $q_{i}$

\begin{tabular}{|c|c|c|c|c|c|}
\hline Calculation & $q_{1}=E$ & $q_{2}=v$ & $q_{3}=\gamma$ & $q_{4}=c$ & $q_{5}=\phi$ \\
\hline 1 & 4 & 2 & 2 & 5 & 3 \\
\hline 2 & 1 & 3 & 5 & 2 & 1 \\
\hline 3 & 3 & 5 & 3 & 4 & 5 \\
\hline 4 & 5 & 1 & 4 & 3 & 4 \\
\hline 5 & 2 & 4 & 1 & 1 & 2 \\
\hline
\end{tabular}

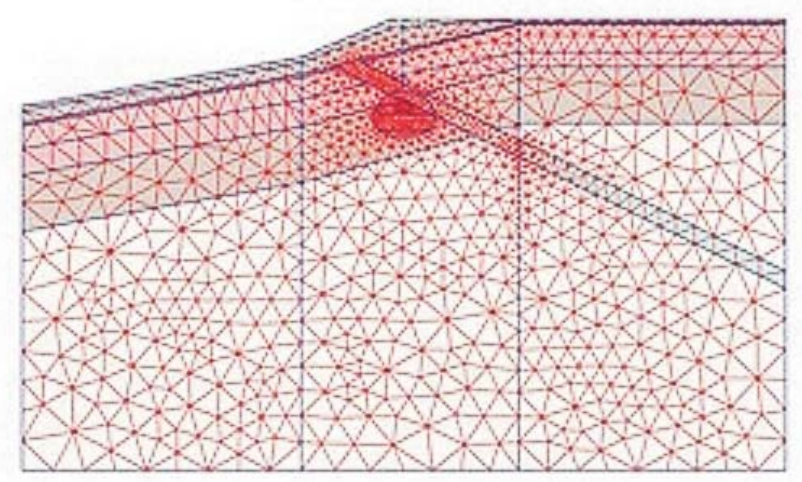

as the tunnel, the project includes underground garages in Letná, four underground Technology Centres and the Trója Bridge. As designed, the excavation will be carried out using the New Austrian Tunnelling Method (NATM). Due to the predicted conditions, a vertical excavation sequence will be adopted in the three-lane tunnel excavation. In the two-lane tunnels, a horizontal excavation sequence is expected.

The position of the exploratory drift has been selected to coincide with the complicated sections of the tunnel to provide information to predicted whether the vertical sequence

Fig. 4: Geometry of generated mesh in WTT km 5.160

should be applied to the top heading only, or to the entire cross section. Mechanical rock breaking is expected, but in combination with the drill-and-blast when passing through the Quartzites. A transition zone between the Quartzites exists at the foot of the slope falling from the Letná Plain. The gradient parameters mean that the tunnels run are in the vicinity of fully saturated Quaternary sediments. A multicriteria analysis resulted in the selection of pre-excavation Table 3: Input parameters for the first run

\begin{tabular}{|c|c|c|c|c|c|}
\hline Parameter $q_{i j}$ & $E_{\text {def }}[\mathrm{MPa}]$ & $v[-]$ & $\gamma\left[\mathrm{kN} / \mathrm{m}^{3}\right]$ & $c[\mathrm{kPa}]$ & $\left.\phi{ }^{\circ}\right]$ \\
\hline Interval number In & 4 & 2 & 2 & 5 & 3 \\
\hline Ground 1 & 4.8 & 0.30 & 17.3 & 11.3 & 26.0 \\
\hline Ground 2 & 13.6 & 0.30 & 18.8 & 5.3 & 28.0 \\
\hline Ground 3 & 24.2 & 0.35 & 20.2 & 14.1 & 23.5 \\
\hline Ground 4 & 79.7 & 0.31 & 22.6 & 22.3 & 27.5 \\
\hline Ground 5 & 171.0 & 0.29 & 24.3 & 45.5 & 32.5 \\
\hline Ground 6 & 271.0 & 0.26 & 25.1 & 91.0 & 36.5 \\
\hline Ground 7 & 421.0 & 0.20 & 25.8 & 91.0 & 36.5 \\
\hline Ground 8 & 24.5 & 0.33 & 23.1 & 13.2 & 26.5 \\
\hline
\end{tabular}


Table 4: Results of the Mrázovka tunnel calculations

\begin{tabular}{|c|c|c|c|c|c|c|}
\hline \multirow[b]{2}{*}{ Calculation } & \multicolumn{2}{|c|}{ Total settlement (mm) } & \multicolumn{2}{|c|}{ Pilot adit settlement (mm) } & \multicolumn{2}{|c|}{$\begin{array}{c}\text { Settlement without the pilot adit } \\
\text { effect }(\mathrm{mm})\end{array}$} \\
\hline & Surface & Tunnel & Surface & Adit & Surface & Tunnel \\
\hline 1 & 79 & 107 & 15 & 8 & 64 & 99 \\
\hline 2 & 153 & 197 & 29 & 14 & 124 & 183 \\
\hline 3 & 92 & 125 & 18 & 10 & 74 & 115 \\
\hline 4 & 85 & 111 & 15 & 8 & 70 & 103 \\
\hline 5 & 134 & 171 & 25 & 12 & 109 & 159 \\
\hline$X$ (average) & 108.60 & 142.20 & 20.40 & 10.40 & 88.20 & 131.80 \\
\hline$s$ (standard deviation) & 29.41 & 35.61 & 5.64 & 2.33 & 23.80 & 33.31 \\
\hline$X+2 s(p=95.45 \%)$ & 167.42 & 213.42 & 31.69 & 15.06 & 135.81 & 198.43 \\
\hline$X-2 s(p=95.45 \%)$ & 49.78 & 70.98 & 9.11 & 5.74 & 40.59 & 65.17 \\
\hline$X+s(p=68.27 \%)$ & 138.01 & 177.81 & 26.04 & 12.73 & 112.00 & 165.11 \\
\hline$X-s(p=68.27 \%)$ & 79.19 & 106.59 & 14.76 & 8.07 & 64.40 & 98.49 \\
\hline VAR $X$ (variance) & 5.69 & 6.22 & 2.65 & 1.75 & 5.15 & 6.02 \\
\hline
\end{tabular}

grouting. The outputs from the exploratory drift near the transition zone (km 5.900 STT) were verified by Latin Hypercube Sampling method [13]. The 2D and 3D numerical analyses were carried out by means of the CESAR - LCPC program system. The rock mass behaviour was approximated by means of the Mohr-Coulomb model. The intervals of the input parameters of the rock mass were determined on the basis of the engineering-geological investigation results. The results of statistical study of South Tunnel Tube (STT) at profile $\mathrm{km} 5.900$ showed that final settlements of the tunnel lining will be between $13 \mathrm{~mm}$ and $347 \mathrm{~mm}$, with a probability of $95 \%$. The range of predicted surface settlements above excavated tunnels is from $7 \mathrm{~mm}$ to $26 \mathrm{~mm}$.

\section{Conclusion}

The results of analyses show the effect of the variation of input parameters describing rock mass behaviour on the results of FEM and demonstrate that the differences from this influence can be significant. The differences in the results flow from variations in the geological conditiond. However, the importance for determination of the final structure behaviour of at least a basic study of the variation of the input parameters can be clearly seen. The Latin Hypercube Sampling method is a procedure with advantages for the qualified statistical evaluation of FE calculation. These methods make significant time saving possible in common statistical methods (Monte Carlo method, estimations of probability moments etc.).

\section{Acknowledgment}

The authors would like to thank to Ministry of Education of the Czech Republic for research project VZ 03 CEZ MSM 6840770003 "Developments of the Algorithms of Computa- tional Simulations and their Application in Engineering" for assistance with a research.

\section{References}

[1] Hudson, J. A.: Rock Engineering Systems: Theory and Practice. Chichester: Ellis Horwood, 1998.

[2] Zadeh, L. A.: Fuzzy Sets, Inform Control, Vol. 8 (1965), p. 338-353.

[3] Dubois, D., Prade H.: Fundamentals of Fuzzy Sets, Norwell, MA, Kluwer, 2000.

[4] Bieniawski, Z. T.: Enngineering Rock Mass Classification. New York: John Wiley and Sons, 1989, ISBN 0-47160172-1

[5] McMahon, B. K.: A Statistical Method for the Design of Rock Slopes. Proceedings $1^{\text {st }}$ Australia - New Zealand Conference on Geomechanics, Vol. 1, Melbourne, Australia, 1971, p. 314-321.

[6] Mahtab, M. A., Grasso, O.: Geomechanics Principles in the Design of Tunnels and Caverns in Rock. Amsterdam: Elsevier, 1992, ISBN 0-4440883088.

[7] Bažant, Z. P., Křístek, V.: The Effect of Shear Lag on Creep Deformation. Journal of Structural Engineering, Vol. 113 (1987), No. 3, p. 557-569.

[8] Et al.: Cesta k pravděpodobnostnímu posudku bezpečnosti, provozuschopnosti a trvanlivosti konstrukcí. In: Spolehlivost konstrukcí 2003 (in Czech), Ostrava. Dům techniky, 2003, ISBN 80-02-01410-3 .

[9] Barták, J., Hilar, M., Pruška, J.: Statistical Analysis of Input Parameters Influence to the Tunnel Deformations Modelling. In: Fourth International Conference on Computational Stochastic Mechanics [CD-ROM]. Houston: Rice University, 2002, p. 280-292. 
[10] Hudek, J.: The Mrazovka tunnels - Measurement and Monitoring at Construction of the WTT - Presiometric Checking on the Success of Saving Grouting - Profiles 003 to 009. Praha: PÚDIS, 1999.

[11] Kolečkář, M., Zemánek I.: Monitoring of the Mrazovka Tunnel. In: Volume of papers of the Int. Conf. Underground Construction 2000, Praha, ITA/AITES, 2000, p. 427-433.

[12] Butovič, A.: Exploratory drift for the Blanka twin tube. Tunel, Vol. 1 (2004), CTuK Praha, 2004, p. 13-18.

[13] Louženský, T.: Mathematical Modeling of Primary Lining Influence on Rock Mass Stress, Prague, CTU in Prague, FCE, Diploma Thesis, 2006 (in Czech).

Doc. Ing. Matouš Hilar, M.SC., Ph.D.

phone/Fax: +420241443411

D2 Consult Prague s.r.o.

Zelený pruh 95/97

14700 Praha 4, Czech Republic

Doc. Dr. Ing. Jan Pruška

phone: +420224344547

Fax: +420224344556

e-mail: Pruska@fsv.cvut.cz

Department of Geotechnics

Czech Technical University in Prague

Faculty of Civil Engineering

Thákurova 7

16629 Praha 6, Czech Republic 